\title{
Preventing Prison Rape: Designing and Validating a PREA Screening Tool for Pre-trial Juvenile Detention Centers
}

\author{
Gina M. Vincent, Ph.D., Associate Professor, John Fitzgerald, Superintendent
}

Patricia Nunez, Program Manager/PREA Coordinator

$\mathrm{R}$ isk assessment and other screening tools can help juvenile justice agencies improve safety for staff and youth. In 2012, national standards of practice for juvenile facilities were implemented in response to the Federal law known as the Prison Rape Elimination Act (PREA; 28 C.F.R. $\$ 115.341),{ }^{1}$ which mandated the implementation of objective screening procedures at juvenile facilities (including group homes and treatment centers that service criminal justice populations) to identify individuals who are at risk of sexual victimization or sexual misconduct. Identification of youth at highest risk of either of these outcomes at entry into a facility enables facility staff to put appropriate interventions into place to reduce the risk of sexual victimization (e.g., placing youth in a room by themselves).

Youth must be PREA screened within 72 hours of admission as part of an overall classification system. These standards provide a list of factors that must be included as part of the screening process, based on research regarding factors associated with institutional sexual abuse (e.g., history of sexual victimization $)^{2}$ and factors linked to vulnerability or victimization (e.g., a youth's physical stature). Facilities were expected to develop and implement a screening tool or procedure relatively quickly; no validation requirements were imposed due to the burden such requirements would place on some smaller facilities. ${ }^{3}$ To date there is no nationally validated instrument for this purpose. As such, most facilities create their own tools, and few have the resources to test the validity and reliability of these instruments.

To address this gap, the State of Connecticut Judicial Branch, Court Support Services Division (CT JBCSSD) designed a PREA screening tool, which was tested in two of their juvenile detention facilities by the National Youth Screening and Assessment Partners (NYSAP). When testing the PREA screening tool, NYSAP and CT JBCSSD wanted to establish two things:

- That the tool was reliable, meaning there is strong agreement in the way the tool is rated across users (e.g., case managers) for the same youth (inter-rater reliability); and

- That the tool was valid, meaning the tool actually measures what it purports to measure, in this case, risk for harming others or being harmed.

This Issue Brief explains the design and validation of the CT JBCSSD PREA screening tool and its validation process to provide guidance to other agencies looking to either a) examine the integrity of their PREA screening tool, or b) adopt the CT JBSCCD version.

\section{Design of a PREA Screening Tool}

The design of a PREA screening tool has some challenges.

- First, the standards list 11 factors that juvenile facilities must include in the screening tool being designed (age, physical size and stature, prior and current convictions, prior sexual victimization or abusiveness, gender nonconforming appearance, level of emotional and cognitive development, mental illness or mental disabilities, intellectual or cognitive disabilities, physical disabilities, the youth's perception of vulnerability, any other relevant information), some of which are grounded in research and some not;

- Second, it is difficult to create a single tool 
that is a valid screen for two very different types of risk (e.g., risk of victimizing others and risk of being victimized); and

- Third, as the standards acknowledge, it is nearly impossible to fully evaluate the validity of a tool that is intended to "predict" an outcome like sexual victimization because such incidents often occur at a very low rate.

The CT JBCSSD PREA screening tool contains the 11 mandated factors as items along with clear definitions as to what criteria must be met for the youth to score low, moderate, or high on each of these items. When developing the tool, designers considered different sets of items to create two separate categories of risk: Risk to Victimize Others and Vulnerability to Victimization. Individuals who score high on any item within one of these risk categories were to be designated as high risk in that category. CT JBCSSD also included a list of "additional factors" for case managers (Classification and Program Officers) to check if present, which are known to indicate a heightened need for supervision or safety precautions, such as:

- Gang affiliation;

- Risk level on the Structured Assessment of Violence Risk for Youth (SAVRY) ${ }^{4}$ a valid assessment instrument for determining adolescents' level of risk of violence and reoffending; and

- Youths' results of the Massachusetts Youth Screening Instrument-Version 2 (MAYSI-2), ${ }^{5}$ a valid self-report measure of suicide risk and potential mental health problems.

Case managers were trained to rate items using information from both youth interviews and collateral sources within 72 hours of a youth's admission to the facility. Case managers were instructed that they could consider these additional factors to increase a youth from low or moderate risk in either Risk to Victimize Others or Vulnerability to Victimization categories. Additional factors could not be used to decrease a high risk level.

\section{Reliability and Validity of the PREA Screening Tool}

\section{Inter-Rater Reliability}

In practice, different staff members within a facility will be using the PREA screen. Therefore, all staff should be trained on how to score and use the screening tool, and items should be written clearly enough to elicit consistent ratings across staff members. We tested the inter-rater reliability of the CT JBCSSD PREA screening tool by having both a trained intern and a case manager independently use the PREA screening tool for the same youth based on the same information. The intern would observe the PREA screening interview conducted with a youth admitted to the facility by a case manager. Then both the intern and case manager reviewed any collateral information, and independently rated the youth. This process was followed for a random sample of 59 youth. Inter-rater reliability for the majority of items on the tool and the overall level of risk for both the Risk to Victimize Others and Vulnerability to Victimization categories was good to excellent, ${ }^{6}$ indicating the tool is objective and has solid agreement between users.

\section{Validity}

Validity refers to the accuracy of the test, or the extent to which a test provides a true measure of the aspect being assessed. In research terms, the objective is to examine the predictive validity - in this case, does the risk level on the tool predict who will actually victimize someone else? We assessed this by investigating the association between PREA risk ratings and whether the youth was written up for an aggressive act (incident) while in one of the CT detention facilities. Some prediction aspects of the tool could not be examined because there were no data to track such incidents or too little data to conduct valid statistical analyses.

Validity for predicting aggressive acts was tested using a random sample of 368 youth ( $46 \%$ were Black and $39 \%$ were White) admitted to two CT detention facilities over a four-month period. The tool classified $22 \%$ of youth as high Risk to Victimize Others and 6\% as having high Vulnerability to Victimization. Youth who had a high rating on any item related to Risk to Victimize Others were almost 4.5 times more likely to initiate a physically aggressive incident against staff or another youth than those with no high item ratings. ${ }^{7}$ 


\section{Effects of Implementation of the PREA Screening Tool}

To determine if using the PREA screening tool actually resulted in any changes in risk management or incidents within the CT juvenile detention facilities, the research team compared outcomes from before and after the tool was implemented. Researchers randomly selected a sample of youth admitted into the juvenile detention centers over a three-month period before the PREA screening tool went into effect, and randomly selected a sample of youth admitted over a three-month period after the PREA screening tool went into place. From these samples, the team matched 178 pre-PREA screening tool youth and 178 post-PREA screening tool youth on characteristics that were significantly related to misconduct in the facilities (e.g., the type of detention facility, ethnicity, gender, alleged offense committed by the youth, history of institutional incidents, and SAVRY risk level) to ensure youth samples were similar in ways that may relate to their behavior. This process enables agencies to isolate the effects of implementing an intervention to the fullest extent possible.

Results indicate that violent or aggressive incidents were cut in half after the PREA screening tool was implemented $(12 \%$ of youth had a violent incident before implementation vs. $5 \%$ after implementation). ${ }^{8}$ Physical and verbal aggression also decreased ( $21 \%$ vs. $12 \%$ of youth, respectively). ${ }^{9}$ There were very few sexual incidents in either group. Results from the PREA screening tool were used to recommend youth for single-room status (which increased from $20 \%$ to $32 \%$ ). It also was paired with some behavior management changes in the detention facilities. Thus, it is likely the PREA screening tool and subsequent changes in procedures accounted for the resulting reduction in incidents.

\section{Summary and Conclusions}

There were a few limitations in our ability to study the PREA screening tool. First, there is no way to tell whether a PREA screening tool can appropriately identify youth who are likely to engage in sexual misconduct in a facility where the occurrence for this type of behavior is already low to begin with. Second, no conclusions could be drawn regarding the predictive validity of the Vulnerability to Victimization ratings because institutional incidents were not documented for the victims. Facilities could initiate this level of documentation in the future if they intend to validate their PREA screening tool.

Through the development of their PREA screening tool, the CT JBCSSD learned that that several factors need to be included to successfully implement such a tool.

1. Facilities should include two separate scoring procedures for the different types of risk identified by a PREA screening tool, as these risks comprise different risk factors;

2. Implementing a training policy to educate new and existing staff on how to use the PREA screening tool will maintain the reliability and integrity of the tool;

3. Using clear item descriptions in the PREA screening tool leads to highly reliable scoring;

4. Including additional risk factors that are known to be associated with risk of victimization or risk of harming others is needed to accurately score a youth;

5. Using the PREA screening tool appears to appropriately recommend single-room status for the right youths, which may lead to a reduction in institutional incidents; and

6. Developing such a screening tool affords facilities the opportunity to implement new behavioral management techniques, which also may lead to fewer institutional incidences.

The CT JBCSSD PREA screening tool may serve as a model for how to design, test, and implement screening tools for use in risk management within youth facilities. Individuals wishing to obtain a copy of the Judicial Branch PREA Classification Screen and accompanying rating manual should contact the State of Connecticut Judicial Branch External Affairs Division at $860-757-2270$ or visit the Connecticut Judicial Branch website: www.jud.ct.gov 


\section{References \& Notes}

${ }^{1}$ U.S. Department of Justice. (2012, June 20). National Standards to Prevent, Detect, and Respond to Prison Rape, 77 Fed. Reg. 119. Retrieved from http://www.prearesourcecenter.org/sites/default/ files/library/2012-12427.pdf

${ }^{2}$ Beck, A. J., Harrison, P. M., \& Guerino, P. (2010, January). Sexual Victimization in Juvenile Facilities Reported by Youth, 2008-09 (U.S. Department of Justice, Bureau of Justice Statistics NCJ 228416). Retrieved from https://www.bjs.gov/content/pub/ pdf/svjfry09.pdf

${ }^{3}$ Hastings, A., McGarry, P., \& diZerega, M. (2013, May). Screening for Risk of Sexual Victimization and for Abusiveness: Guidelines for Administering Screening Instruments and Using the Information to Inform Housing Decisions. Vera Institute of Justice. Retrieved from https://www. prearesourcecenter.org/sites/default/files/library/ preascreeningguidelines.pdf

${ }^{4}$ Borum, R., Bartel, P., \& Forth, A. (2006). Manual for the Structured Assessment for Violence Risk in Youth (SAVRY). Tampa, FL. Florida Mental Health Institute, University of South Florida.

${ }^{5}$ Grisso, T. \& Barnum, R. (2006). Massachusetts Youth Screening Instrument-Version 2: User's Manual and Technical Report. Sarasota, FL: Professional Resource Press.

${ }^{6}$ ICC stands for intra-class correlation coefficient, a common index used to quantify level of agreement on an instrument.

${ }^{7} \mathrm{x} 2(1)=12.29, \mathrm{p}<.001$

${ }^{8} \mathrm{x} 2(1, \mathrm{~N}=356)=5.24, \mathrm{p}=.02$; odds ratio $=.40$

${ }^{9} \mathrm{x} 2(1, \mathrm{~N}=356)=4.571, \mathrm{p}=.03$; odds ratio $=.54$ 